\title{
PROCESSAMENTO DE AMIDO DE MILHO EM CÂMARA DE MISTURA ${ }^{1}$
}

\author{
Marcia C. SILVA², Rossana M.S.M. THIRÉ3 ${ }^{3}$ Victor J.R.R. PITA³, \\ Carlos W.P. CARVALHO ${ }^{4}$, Cristina T. ANDRADE ${ }^{2,3, *}$
}

\begin{abstract}
RESUMO
Misturas de amido de milho e água nas proporções 70:30, 80:20 e 90:10\% (p/p) foram submetidas a processamento a 90 ${ }^{\circ} \mathrm{C}$, sob diferentes velocidades de rotação (20,40, 80 e 100rpm), em câmara de mistura Rheomix 600 equipada com rotores do tipo "roller". A influência do teor de água e da velocidade de rotação dos rotores no processamento do amido de milho foi investigada por meio de curvas de torque e de temperatura fornecidas pelo reômetro de torque Rheocord 9000. Análises em Analisador Rápido de Viscosidade e por microscopia óptica de luz polarizada foram realizadas, a fim de complementar as informações registradas pelas curvas de torque e de temperatura. Os resultados mostraram que o teor de água e a rotação empregada no processamento exercem influência significativa nas características do amido processado. Os menores teores de água (10 e $20 \% \mathrm{p} / \mathrm{p}$ ) e as velocidades de rotação mais elevadas ( 80 e 100 rpm) contribuíram para a maior degradação do amido. Nas misturas com teor de água de 30\% (p/p), sob as velocidades de rotação empregadas, a função plastificante da água contribuiu para minimizar o efeito do cisalhamento, já que a degradação do amido não foi observada. Nesses casos, a estrutura granular do amido foi preservada em grande parte durante o processamento.

Palavras-chave: amido de milho; câmara de mistura; reometria de torque; viscosidade; microscopia óptica.
\end{abstract}

\section{SUMMARY}

PEOCESSING OF CORN STARCH IN AN INTERNAL MIXER. Corn starch/water mixtures at compositions of 70:30, 80:20 and 90:10 (w/w \%) were submitted to processing at $90^{\circ} \mathrm{C}$ and different rates $(20,40,80$ and 100rpm) in an internal mixer (Rheomix 600), equipped with counter-rotating roller type rotors. The effect of the water content and of the rotation rate on the starch processing was investigated by torque and temperature curves given by the in-line Rheocord 9000 torque rheometer. Viscosity measurements, carried out in a Rapid Visco Analyser (RVA), and optical microscopy analysis were performed on the processed samples to complement the rheometry data. The results indicated that the water content and the rotation rate had a significant effect on the characteristics of the processed starch samples. For compositions with 10 and $20 \%(\mathrm{w} / \mathrm{w})$ water contents and processed at 80 and $100 \mathrm{rpm}$, degradation was observed at a larger extent. For compositions in which water had been added at a $30 \%(\mathrm{w} / \mathrm{w})$ content, its plastifying property contributed to minimize degradation caused by mechanical and thermal inputs. In these cases, the granular structure of starch was largely preserved.

Keywords: corn starch; internal mixer; torque rheometry; viscosity; optical microscopy.

\section{1 - INTRODUÇÃO}

O amido é o principal material de reserva do reino vegetal e a principal fonte de carboidratos disponível para a alimentação humana. É largamente utilizado na indústria alimentícia e, em menor escala, pelas indústrias farmacêutica e têxtil [18]. Os grânulos de amido são constituídos principalmente por dois polissacarídeos, amilose e amilopectina, ambos formados por unidades constitucionais repetitivas de $\alpha$-D-glicose. A amilose é uma molécula essencialmente linear, enquanto que a amilopectina é um polissacarídeo altamente ramificado [4].

\footnotetext{
Recebido para publicação em 04/12/2003. Aceito para publicação em 12/05/2004 (001257).

2. Instituto de Química, Universidade Federal do Rio de Janeiro, Centro de Tecnologia, Bloco A, Cidade Universitária, Ilha do Fundão, CEP: 21949 900 Rio de Janeiro, RJ.

3. Instituto de Macromoléculas Professora Eloisa Mano, Universidade Federal do Rio de Janeiro, Centro de Tecnologia, Bloco J, Cidade Universitária, Ilha do Fundão, Caixa Postal 68525, CEP: 21945-970 Rio de Janeiro, RJ. E-mail: ctandrade@ima.ufrj.br. Tel: (21) 2562-7208 / (21) 2562-8263

4. EMBRAPA Agroindústria de Alimentos, Avenida das Américas 29501, Guaratiba, CEP: 23020-470 Rio de Janeiro, RJ

* A quem a correspondência deve ser enviada.
}

$\mathrm{Na}$ área de alimentos, o amido consiste na principal matéria-prima para a fabricação de produtos extrusados. "Snacks", cereais matinais, biscoitos, massas pré-cozidas e alimentos prontos para o consumo são alguns exemplos de produtos usualmente processados por tratamentos do tipo calor/umidade, como extrusão, cocção no forno ou cocção sob alta pressão [12, 14]. O amido confere ao produto final características típicas como alta expansão e crocância, muito apreciadas pelo consumidor. Estas características estão relacionadas ao efeito da interação do amido com a água, associado à energia mecânica e térmica gerada durante o processo de extrusão.

A principal conseqüência do tipo de tratamento calor/umidade para produtos amiláceos é a gelatinização dos grânulos de amido [14]. Além da gelatinização, as macromoléculas do amido podem sofrer degradação, devido aos tratamentos térmico e mecânico empregados [1].

Os grânulos de amido, quando aquecidos em presença de água acima de uma determinada temperatura, formam uma suspensão viscosa. A temperatura na qual ocorre tal modificação é denominada de temperatura de gelatinização do amido. A gelatinização é definida como o colapso da ordenação granular, durante a qual ocorrem mudanças irreversiveis nas propriedades, como o inchamento dos grânulos, a fusão cristalina, a perda da birrefringência, o rompimento dos grânulos com a liberação da amilose e o aumento da viscosidade da suspensão $[3,8,10,15,19,20,23]$. 
O processamento preliminar do material em câmara de mistura acoplada a um reômetro de torque é capaz de fornecer um indicativo das condições iniciais a serem utilizadas no processo de extrusão, o que permite a sua otimização. Além disso, trata-se de um método vantajoso, uma vez que fornece respostas imediatas com volume menor de amostra quando comparado com o processamento em extrusora [5].

O objetivo do presente trabalho foi avaliar a influência do teor de água e da velocidade de rotação dos rotores no processamento do amido de milho em câmara de mistura. O comportamento das misturas amido/água foi investigado por meio de curvas de torque, obtidas pelo processamento em câmara de mistura acoplada a reômetro de torque. Os resultados foram complementados com medidas de viscosidade de pasta e dados de microscopia óptica.

\section{2 - MATERIAIS E MÉTODOS}

\section{1 - Material}

O amido de milho utilizado foi fornecido pela Corn Products do Brasil (São Paulo, Brasil) e continha um teor de umidade de $12,5 \%$.

\section{2 - Métodos}

\subsection{1 - Preparação das amostras}

Misturas de amido de milho e água destilada foram preparadas nas proporções de 70:30, 80:20 e 90:10\% (p/p). Essas misturas foram condicionadas a $18^{\circ} \mathrm{C}$ por 24 a 48h, a fim de permitir a completa absorção da água.

\subsection{2 - Processamento em câmara de mistura}

As amostras foram processadas durante $1 \mathrm{~h}$ sob temperatura constante de $90^{\circ} \mathrm{C}$ em câmara de mistura modelo Rheomix 600, equipada com rotores tipo "roller", e acoplada ao reômetro de torque Rheocord 9000 (Haake, Karlsruhe, Alemanha). Diferentes rotações, na faixa de 20 a 100rpm foram utilizadas nesse processamento.

Curvas de torque e de temperatura em função do tempo de mistura foram registradas ao longo de cada processamento, a fim de avaliar-se o comportamento de fluxo da mistura. A área sob as curvas de torque podem ser relacionadas à energia absorvida pelo material durante o processamento [9]. O torque medido está relacionado à viscosidade do material durante o processamento, ou seja, corresponde à resistência do material ao fluxo [5].

\subsection{3 - Condicionamento e moagem das amos- tras}

Após o processamento, as amostras foram condicionadas a $18^{\circ} \mathrm{C}$ por quatro meses, secas em estufa Ética Indi-30 (São Paulo, Brasil) por 15 horas a $50^{\circ} \mathrm{C}$, submetidas à moagem em moinho de disco Perten Instruments modelo 3600 (Huddinge, Suiça) com abertura seis e, pos- teriormente, em moinho de rolo Brabender tipo QU-J (Duisburg, Alemanha). A moagem teve como objetivo reduzir o tamanho de partícula e tornar o material mais uniforme.

\subsection{4 - Propriedades de pasta}

As amostras moídas foram analisadas no Analisador Rápido de Viscosidade (Rapid Visco Analyser, RVA, Newport Scientific Pty. Ltd., Warriewood, Austrália), o qual foi usado para medir a viscosidade de pasta aparente das amostras em função da temperatura. Para $3 g$ de cada amostra (umidade ajustada para 14\% em base úmida) foram adicionados $25 \mathrm{~g}$ de água destilada. A suspensão formada pelo amido e a água foi inicialmente cisalhada a 960rpm durante 10s. Para a medida propriamente dita, a suspensão foi mantida a $25^{\circ} \mathrm{C}$ por 4 minutos, para que se pudesse investigar a viscosidade do amido a baixa temperatura [25]. Posteriormente, a mistura foi aquecida a $95^{\circ} \mathrm{C}$ sob velocidade constante de $14^{\circ} \mathrm{C} / \mathrm{min}$, mantida nesta temperatura por $3 \mathrm{minu}-$ tos, resfriada a $25^{\circ} \mathrm{C}$ durante 5 minutos sob a mesma velocidade, e mantida a $25^{\circ} \mathrm{C}$ por mais 4 minutos, totalizando 23 minutos de análise, a 160rpm.

\subsection{5 - Análise por microscópica óptica}

A morfologia das amostras após a moagem foi analisada por microscopia óptica. As imagens foram obtidas em microscópio óptico com luz polarizada Olympus modelo BX50 (Olympus America Inc., New York, EUA), acoplado a uma câmara fotográfica Olympus.

\section{3 - RESULTADOS E DISCUSSÃO}

\section{1 - Avaliação do processamento em câmara de mistura}

A Figura 1 mostra a variação do torque (a) e da temperatura (b) ao longo de 20 minutos de processamento de misturas amido/água na razão de 80:20\% (p/p) com velocidades de rotação de 20, 40, 80 e 100rpm. Esses resultados mostram que a rotação empregada exerce influência significativa no comportamento do torque.

As curvas da Figura la podem ser analisadas com base nas considerações de BYRNE [5], que descreveu uma curva típica em reômetro de torque, na qual dois máximos podem ser observados. O primeiro máximo de torque pode estar associado à compactação do material e ao início do processamento. Um segundo máximo, quando ocorre, pode indicar a degradação do material. As curvas relacionadas ao processamento a 20 e $40 \mathrm{rpm}$ mostram que o valor do torque foi relativamente estabilizado após o primeiro máximo (pico de compactação), o que indica homogeneização da mistura. Com a estabilização do torque, a temperatura da mistura tendeu ao valor pré-estabelecido de $90^{\circ} \mathrm{C}$ (Figura $1 \mathrm{~b}$ ).

Quando a rotação foi elevada a 80rpm e a 100rpm, a energia gerada pelo sistema parece ter ocasionado a degradação parcial do amido. O segundo máximo observado na curva de torque está associado a um au- 
mento de aproximadamente $17^{\circ} \mathrm{C}$ na temperatura da mistura (Figura 1b), o que deve ter levado à perda de água pelo sistema por evaporação.
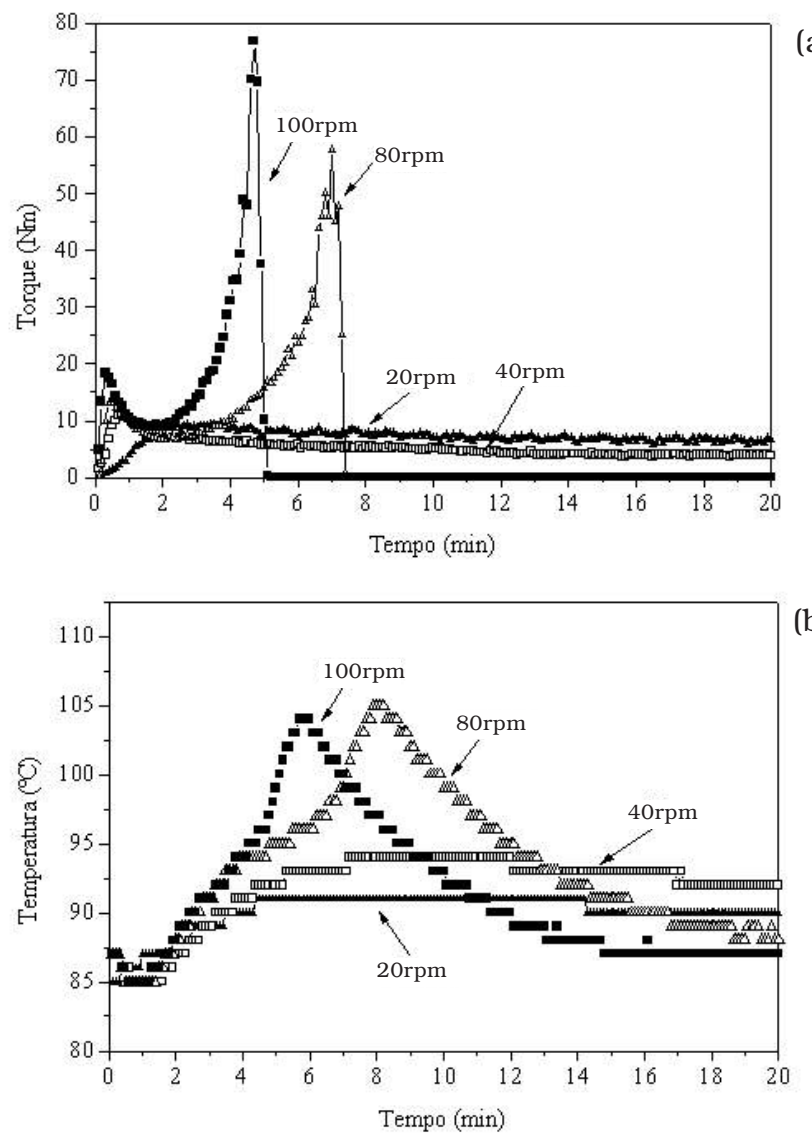

FIGURA 1. Curvas de torque (a) e de temperatura (b) obtidas em reômetro de torque durante o processamento de amido de milho/água $80: 20 \%(\mathrm{p} / \mathrm{p})$ sob diferentes velocidades de rotação.

Essa hipótese é consistente com o fato de que outros autores verificaram que elevados niveis de energia mecânica e térmica desenvolvidos durante a extrusão do amido podem levar ao decréscimo da massa molar das macromoléculas constituintes do amido ou à dextrinização, situação na qual o grau de ramificação é aumentado $[6,7,11,13]$. Após o máximo de degradação, o torque tendeu a zero, uma vez que, com a evaporação da água, os grânulos secos de amido não ofereceram mais resistência ao cisalhamento. Para rotações de 20 e 40rpm, não foi observado o pico de degradação do amido, mesmo para tempos de processamento maiores do que $1 \mathrm{~h}$. Com base nestes resultados, pode-se supor que o amido só seria degradado se submetido a processamento por períodos de tempo mais longos.

As curvas de torque (a) e de temperatura (b) obtidas durante o processamento da mistura de amido com menor teor de água, na razão 90:10\% (p/p) e sob diferentes velocidades de rotação podem ser visualizadas na Figura 2. As curvas da Figura $2 a$ mostram que os valores de torque desenvolvidos foram mais elevados quando comparados aos resultados obtidos para as amostras com adição de $20 \%$ de água (Figura 1a). Este fato era esperado, tendo-se em vista que a gelatinização/fusão em presença de pequena quantidade de água é dificultada, e necessita de maior energia para que ocorra. Na Figura $2 a$, podem ser observados períodos de estabilidade do torque extremamente curtos, sendo a degradação do amido claramente evidenciada sob as velocidades de rotação empregadas. Assim como nas misturas contendo 20\% (p/p) de água (Figura 1), os picos indicativos de degradação do amido foram acompanhados por elevação da temperatura da mistura (Figura 2b) e sofreram um deslocamento para tempos menores em função do aumento da velocidade de rotação; quanto mais elevada a rotação, mais cedo o pico foi detectado.

Outro fato importante a ser ressaltado é o surgimento de picos intermediários nas curvas de torque (indicados por setas) entre os picos de compactação e de degradação. Com o aumento da velocidade de rotação, a intensidade e a largura do pico intermediário diminuem e, com a rotação mais elevada (100rpm), mais de um pico intermediário podem ser observados. Esses picos intermediários podem estar relacionados à formação e, em seguida, à desestruturação de aglomerados, causadas pelo cisalhamento. No entanto, de acordo com a Figura $2 b$, o perfil de temperatura não sofreu variação significativa em função do aparecimento desses picos.

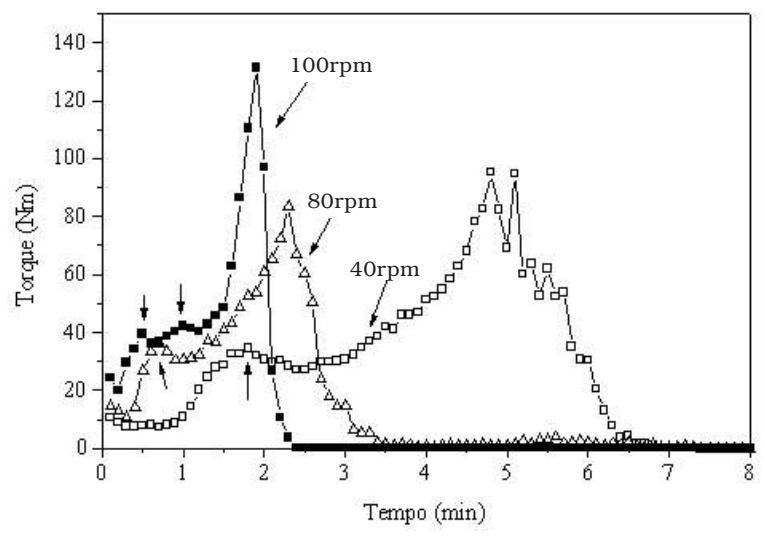

(a)

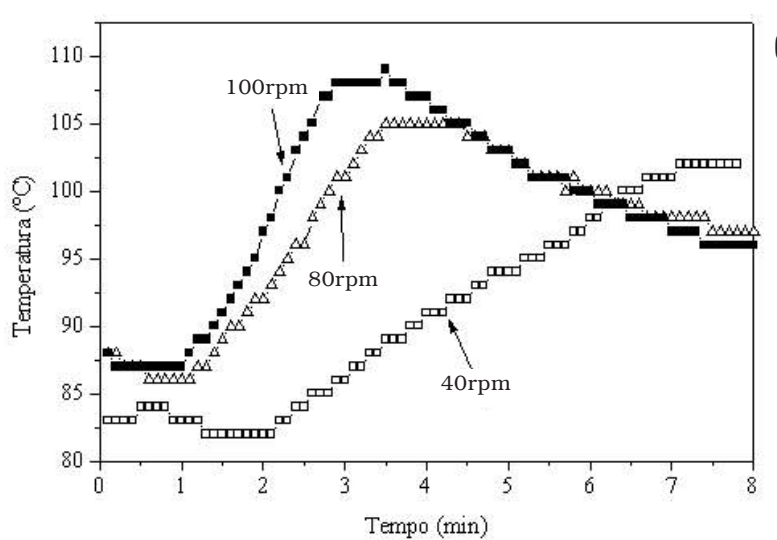

(b)

FIGURA 2. Curvas de torque (a) e de temperatura (b) obtidas em reômetro de torque durante o processamento de misturas de amido de milho e água a 90:10\% (p/p) sob diferentes velocidades de rotação. 
Independentemente da rotação utilizada, após o processamento das misturas de amido com adição de $10 \%$ e $20 \%$ de água, o produto final foi obtido sob a forma de pó.
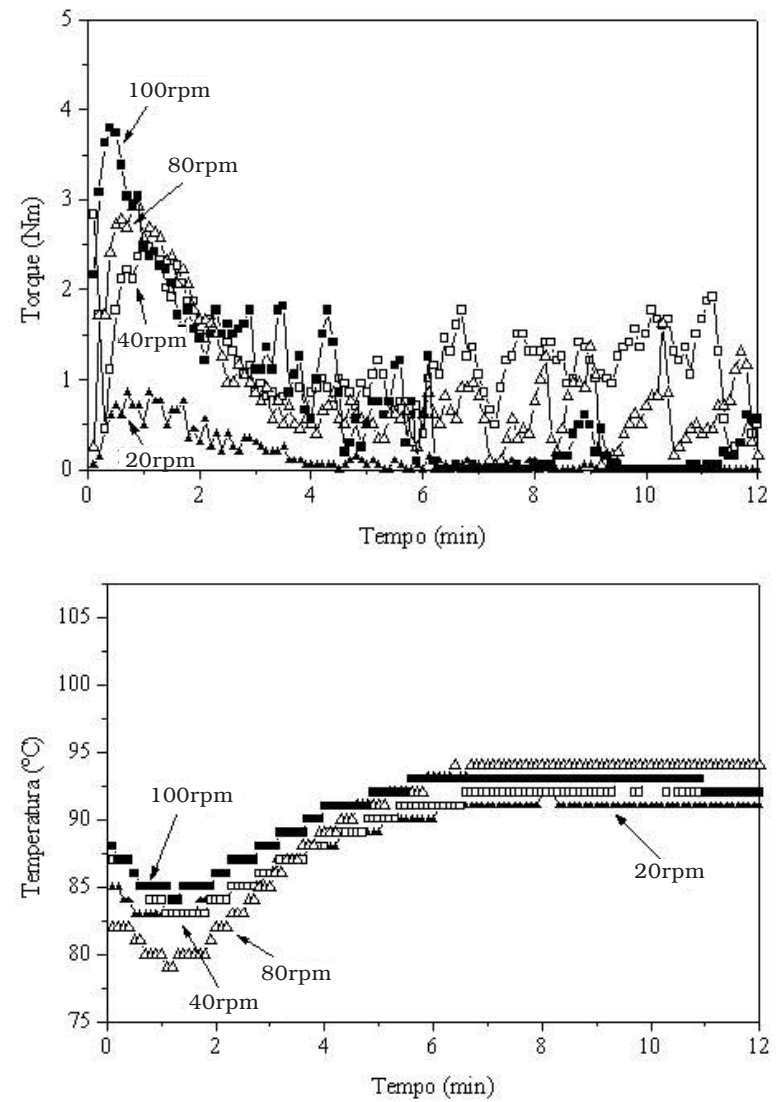

(b)

FIGURA 3. Curvas de torque (a) e de temperatura (b) obtidas em reômetro de torque durante o processamento de misturas de amido de milho e água a 70:30\% (p/p) sob diferentes velocidades de rotação.

Na Figura 3, são apresentadas as curvas de torque (a) e de temperatura (b) de misturas de amido e água na proporção de $70: 30 \%(\mathrm{p} / \mathrm{p})$ processadas a diferentes velocidades de rotação. De acordo com a Figura 3a, com maior proporção de água, o torque desenvolvido foi muito baixo, quando comparado com os resultados apresentados anteriormente. O valor máximo observado foi de $3,79 \mathrm{Nm}$, obtido durante o processamento a 100rpm. Este comportamento pode ser explicado com base na plastificação do amido pela água. A água age como um plastificante do amido, aumentando a mobilidade das moléculas e, assim, diminuindo a temperatura de transição vítrea [17]. É razoável supor-se que, com o aumento do teor de água, as forças de interação entre as macromoléculas constituintes do amido tenham decrescido e a mobilidade de suas cadeias tenha aumentado, o que teria tornado o material mais flexível. Nesse caso em particular, sob a temperatura de $90^{\circ} \mathrm{C}$, seria razoável supor-se que, logo nos primeiros minutos, os grânulos tenham sofrido um inchamento significativo. Como o material não ofereceu resistência aos rotores, o torque desenvolvido durante o processamento tendeu a um valor muito baixo.
As curvas de torque mostraram também que após um primeiro pico, o torque tendeu a zero, com algumas oscilações. Esse perfil não sofreu modificação no decorrer de $1 \mathrm{~h}$ de processamento. As oscilações no valor do torque podem ser resultantes da formação de aglomerados em determinados pontos da câmara. No entanto, conforme apresentado na Figura 3b, após o pico de compactação, a temperatura permaneceu constante ao longo de todo o processamento. Considerando uma outra hipótese, devido ao seu estado borrachoso, a pasta poderia estar alternadamente aderida e solta dos rotores e das paredes do misturador, o que acarretaria um aumento e, em seguida, um decréscimo da resistência à rotação.

\section{2 - Viscosidade de pasta}

O uso do RVA é recomendado para o estudo do comportamento de pasta, uma vez que requer uma pequena quantidade de amostra e curto período de tempo de análise [24]. Os resultados obtidos por meio do RVA fornecem informações sobre o grau de degradação do amido, a gelificação e o inchamento [22].

Conforme citado anteriormente, após o processamento em câmara de mistura, as amostras com teores iniciais de água menores do que $30 \%(\mathrm{p} / \mathrm{p})$ foram obtidas sob a forma de pó, enquanto que as demais se apresentaram sob a forma de uma massa úmida. Assim, a moagem foi realizada com o intuito de padronizar a morfologia das amostras processadas, uma vez que as análises de RVA podem ser influenciadas pela distribuição de tamanho das partículas e pela forma dos aglomerados [2]. Como o tratamento de moagem pode induzir a conversão física dos grânulos de amido, o que resulta em mudança de propriedades similar à gelatinização [16], o mesmo procedimento de moagem foi adotado para todas as amostras processadas, independentemente do aspecto morfológico do produto final.

Na Figura 4, podem ser comparados os perfis dados pelas medidas no RVA para amido de milho granular moído e para as amostras processadas em câmara de mistura a 20rpm (a) e 40rpm (b). As curvas de amido de milho granular não exibem viscosidade inicial a frio $\left(25^{\circ} \mathrm{C}\right)$. O aumento da temperatura leva à gelatinização do amido, o que provoca o aumento abrupto da viscosidade em função da presença das moléculas de amilose liberadas para a suspensão e dos grânulos de amido inchados. Com a continuidade do experimento a $95^{\circ} \mathrm{C}$, a queda da viscosidade pode ser atribuída ao alinhamento das moléculas de amilose sob cisalhamento. Com a diminuição da temperatura, observa-se um novo aumento na viscosidade (setback) devido à gelificação e retrogradação das moléculas de amilose. A viscosidade a $95^{\circ} \mathrm{C}$ das amostras processadas foi menor do que a do amido de milho granular, muito provavelmente devido à degradação parcial do amido durante o processamento. $\mathrm{O}$ aumento do teor de água contribuiu para a menor degradação do amido e para uma maior viscosidade a $95^{\circ} \mathrm{C}$ e após o resfriamento, o que confirma os dados obtidos a partir das curvas do reômetro de torque (Figura 3). 

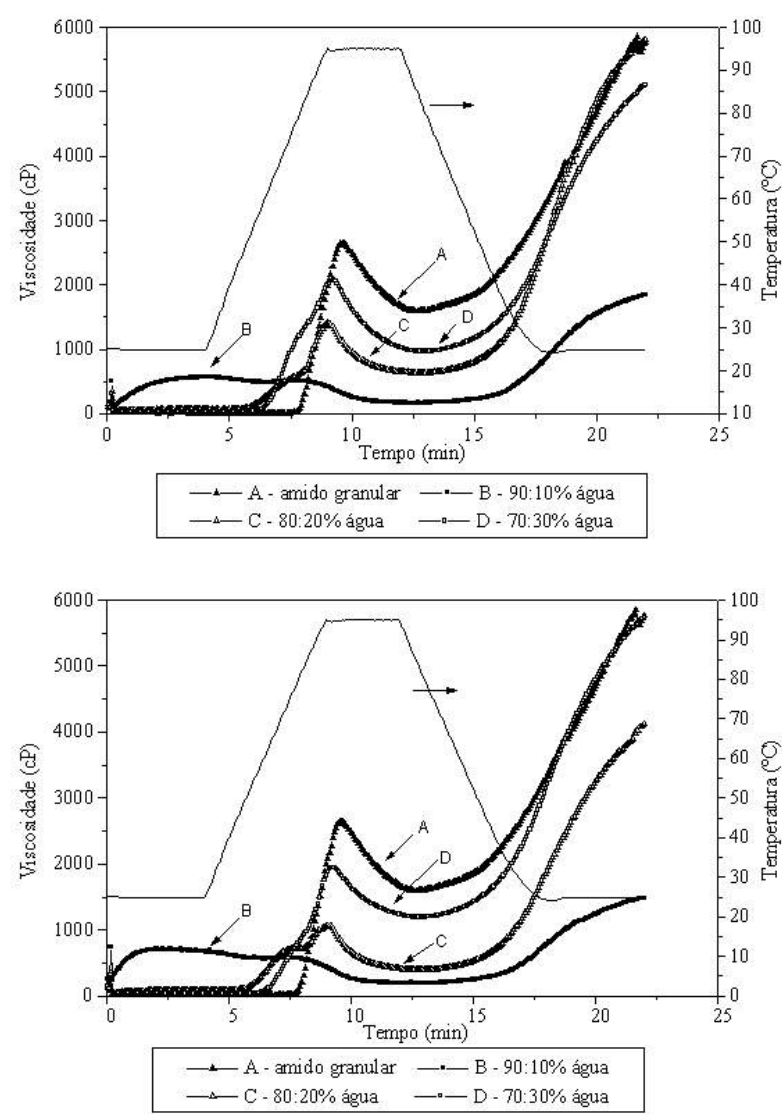

FIGURA 4. Perfil de RVA para amido de milho granular moído e para as amostras processadas a $20 \mathrm{rpm}$ (a) e 40rpm (b) com diferentes proporções de água.

Os resultados da Figura 4 mostram também que as amostras com adição de $10 \%(\mathrm{p} / \mathrm{p})$ de água apresentaram viscosidade a frio $\left(25^{\circ} \mathrm{C}\right)$ mais elevada do que as demais amostras (20 e 30\% p/p de água). WHALEN et al. [25] utilizaram perfis de RVA para avaliar o efeito das condições de extrusão do amido de milho e verificaram que a diminuição no teor de água durante o processamento acarreta um maior grau de degradação do amido e o aumento na viscosidade a frio $\left(25^{\circ} \mathrm{C}\right)$. A viscosidade a frio foi relacionada à presença de grânulos de amido altamente inchados, que permaneceriam insolúveis na suspensão, de amilose e amilopectina de massa molar elevada ou à presença de dextrinas [25]. No presente caso, parece mais razoável explicar os resultados diferenciados das viscosidades a baixa temperatura em relação aos dados fornecidos pelas curvas de torque. Com $10 \%(\mathrm{p} / \mathrm{p})$ de água, o processo de fusão predomina (em relação à gelatinização) e acarreta a quebra dos grânulos, associada à degradação das macromoléculas. O máximo de degradação foi observado no processamento sob todas as rotações (Figura 2). As viscosidades a frio mais elevadas parecem indicar que o processamento favoreceu a quebra de grânulos; com a quebra, as macromoléculas constituintes do amido são mais facilmente liberadas para a suspensão, e passam a contribuir para a viscosidade, mesmo a temperaturas mais baixas. Com o aumento da temperatura $\left(95^{\circ} \mathrm{C}\right)$ durante a análise, observa-se o decréscimo da viscosidade para as amostras com 10\% (p/p) de água. Nesses casos, sem a presença extensiva de grânulos intactos, a gelatinização não mais é observada nas curvas de RVA. A degradação ocorrida durante o processamento pode ser verificada pela viscosidade mais baixa (rede tridimensional do gel mais fraca) após o resfriamento.

Nas amostras com 20 e 30\% (p/p) de água não se observa viscosidade a $25^{\circ} \mathrm{C}$, o que indica a presença de uma grande quantidade de grânulos intactos. Sob essas condições, o amido granular residual não sofreria gelatinização. No entanto, a $95^{\circ} \mathrm{C}$, essas amostras apresentaram viscosidade mais próxima às amostras de amido de milho granular não processado. Pode-se dizer que, sob aquecimento, o amido granular residual sofreu gelatinização, já que para a análise no RVA as quantidades de água e de calor fornecidas ao sistema foram razoavelmente elevadas.

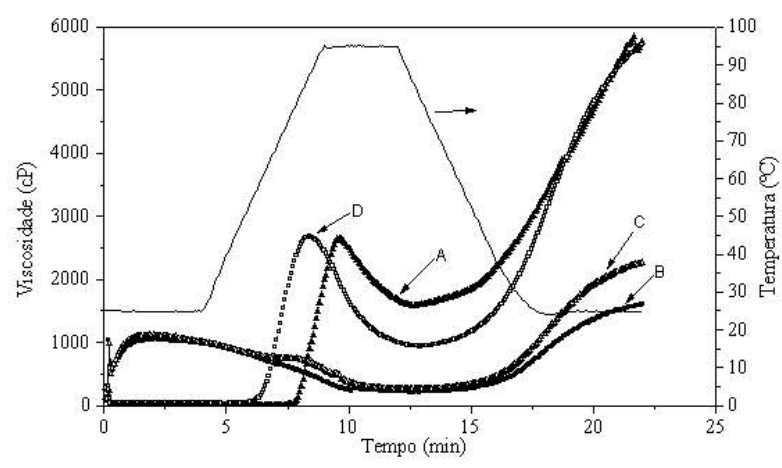

(a)

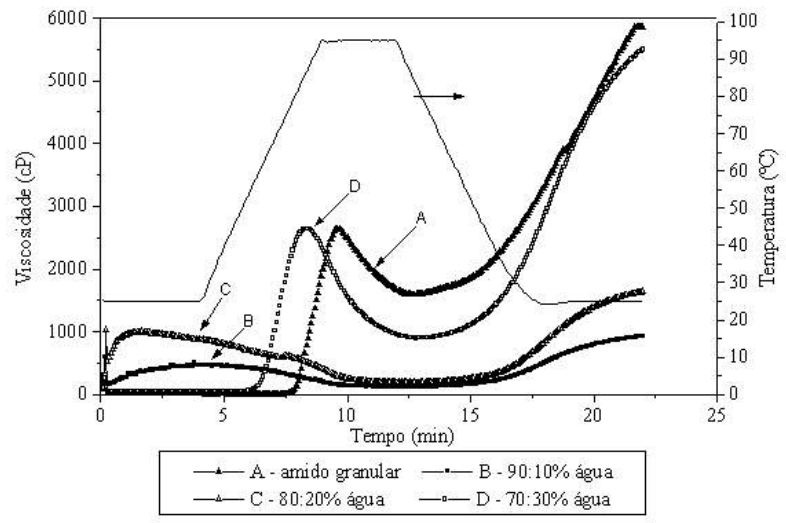

(b)

FIGURA 5. Perfil de RVA para amido de milho granular moído e para as amostras processadas a 80rpm (a) e 100rpm (b) com diferentes proporções de água.

A Figura 5 mostra perfis de RVA para o amido granular e para as amostras processadas em câmara de mistura a 80rpm (a) e a 100rpm (b). O amido de milho granular e o processado com 30\% (p/p) de água mantiveram perfis semelhantes aos observados anteriormente (Figura 4). É interessante notar que os máximos correspondentes à gelatinização, nesses casos em que a rotação foi mais elevada, ocorrem mais cedo para o amido processado. 
Para o amido processado com 10\% (p/p) de água, os resultados de RVA também se assemelham àqueles discutidos anteriormente (Figura 4). No entanto, quando a água foi adicionada a $20 \%(\mathrm{p} / \mathrm{p})$, foi observado um comportamento mais próximo à amostra processada com $10 \%(\mathrm{p} / \mathrm{p})$ de água. Nesses casos, pode-se verificar que sob rotações mais elevadas, o processamento não só levou à degradação (Figura 1), a qual tem efeito direto sobre a viscosidade do gel (viscosidade baixa a $25^{\circ} \mathrm{C}$, após o aquecimento seguido de resfriamento), como também à quebra de grânulos, evidenciada pela viscosidade mais elevada no início do experimento, a $25^{\circ} \mathrm{C}$, e pela ausência do máximo correspondente à gelatinização.

\section{3 - Microscopia}

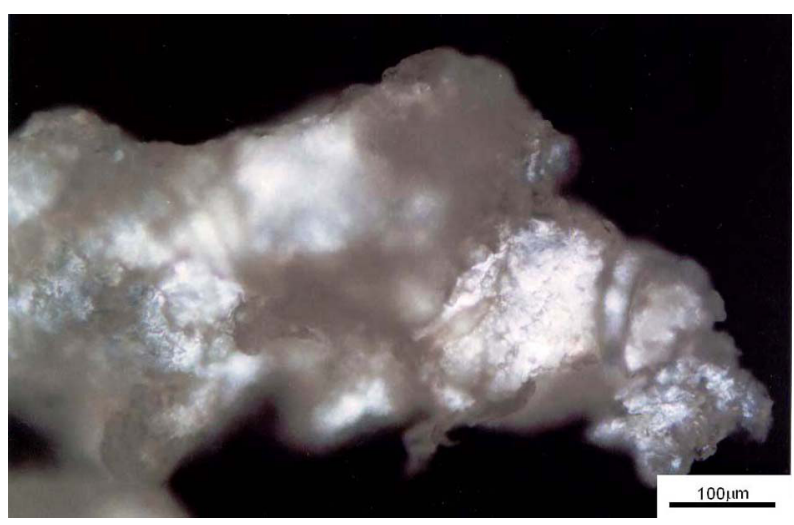

(a)

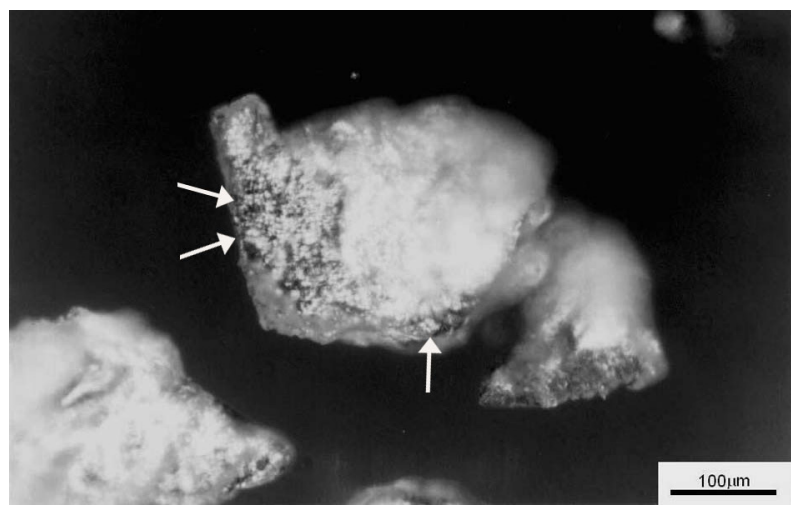

(c)

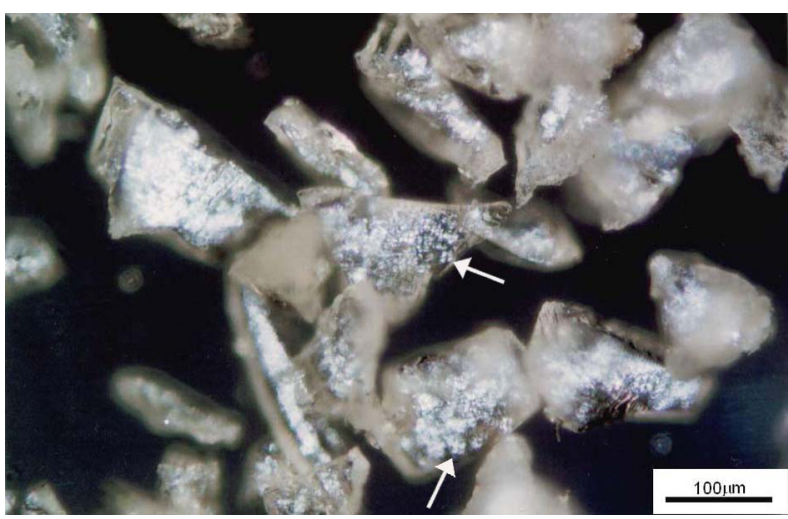

(e)
Na Figura 6, são apresentadas micrografias ópticas sob luz polarizada da superfície das misturas com proporção de água de $10 \%$ (a, b), 20\% (c, d) e 30\% (e, f) após o processamento a 40rpm (a, c, e) e 100rpm (b, d, f) e moagem.

Nas micrografias das amostras com 30\% de água (Figuras $6 e$ e 6f), podem ser identificadas estruturas birrefringentes, denominadas cruzes de Malta (indicadas por setas), independentemente da velocidade de rotação utilizada no processamento. Essas estruturas são características dos grânulos de amido, não fundidos, e são visíveis sob luz polarizada devido ao alto grau de organização supramolecular dos grânulos. Essa observação corrobora os resultados obtidos no reômetro

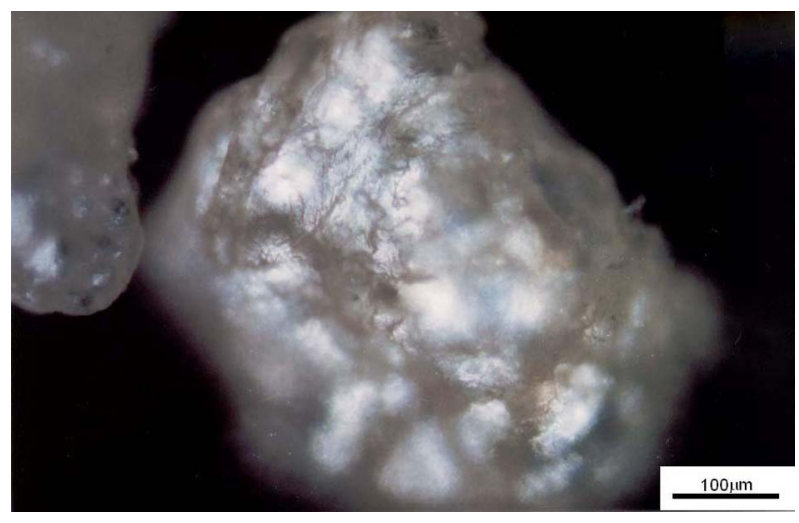

(b)
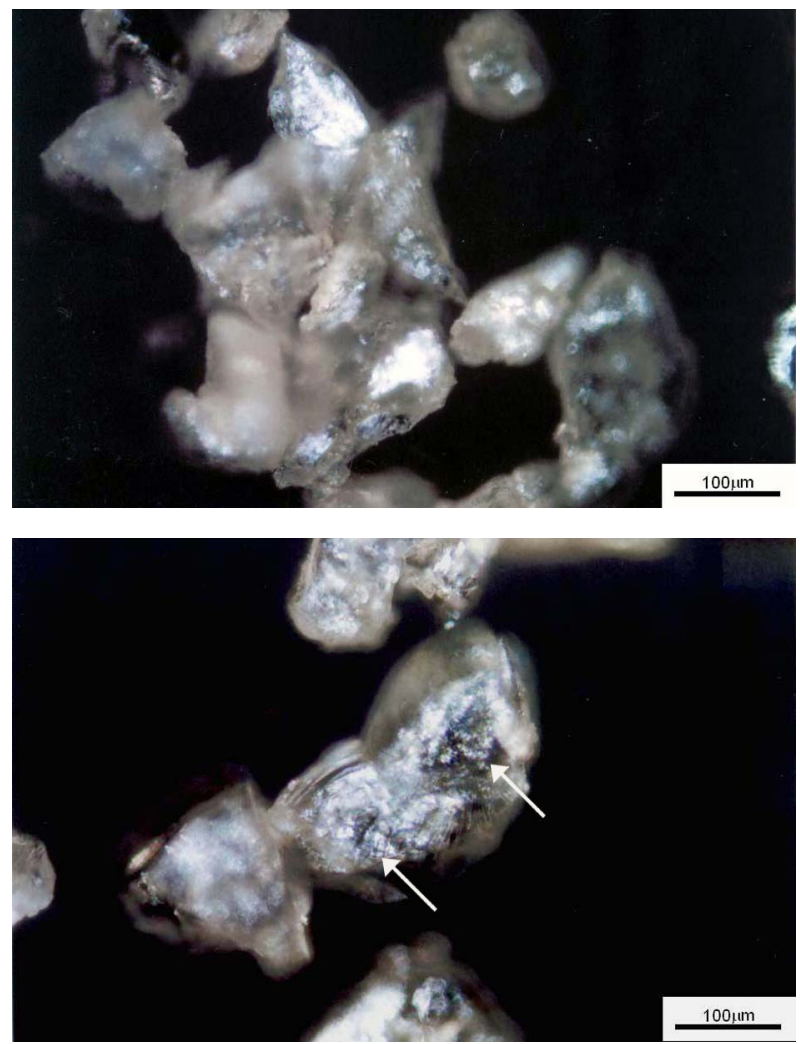

FIGURA 6. Micrografias ópticas sob luz polarizada da superfície das misturas com proporção de água de 10\% (a, b), 20\% (c, d) e $30 \%(e, f)$ após o processamento a $40 \operatorname{rpm}(\mathrm{a}, \mathrm{c}, \mathrm{e})$ e $100 \mathrm{rpm}(\mathrm{b}, \mathrm{d}, \mathrm{f})$. 
de torque (Figura 3) e no RVA (Figuras 4 e 5), os quais mostram que em presença de teores de água mais elevados, o grau de degradação do amido é reduzido significativamente.

A premissa de que o aumento do torque após um período de estabilidade pode estar relacionado à degradação do material pode ser confirmada pelas micrografias das misturas amido/água 90:10\% (p/p), processadas a 40 e a 100rpm (Figuras 6a e 6b); grânulos intactos não são observados na superfície dessas amostras. A comparação desses resultados com os perfis de RVA, apresentados nas Figuras 4 e 5, permite que se reafirme que, nessas condições, ocorreu a fusão parcial do amido e que o produto final moído é constituído por grânulos intactos em quantidade muito pequena e por fragmentos de grânulos.

Nas misturas com 20\% de água (Figuras 6c e 6d), as cruzes de Malta (indicadas por setas) só foram visualizadas nas amostras processadas a velocidades mais baixas (Figura 6c). As micrografias também corroboram os resultados obtidos a partir das curvas de torque ( $\mathrm{Fi}^{-}$ gura 1) e dos perfis de RVA (Figuras 4 e 5).

Além das cruzes de Malta, o contorno dos fragmentos das amostras pode ser claramente visualizado sob luz polarizada. Este fato pode ser um indício do grau de cristalinidade das amostras. Esta cristalinidade pode estar relacionada à ordenação do tipo $\mathrm{B}$, decorrente da retrogradação das moléculas de amilose durante os processos de secagem e/ou moagem; cristalinidade do tipo $\mathrm{V}$, decorrente da formação de complexos entre lipídios e amilose e/ou do tipo $\mathrm{E}_{\mathrm{h}}$, relacionado à cristalização do complexo amilose-amilopectina a partir de fundidos com baixo teor de umidade [21].

\section{4 - CONCLUSÕES}

No processamento de materiais amiláceos, algumas condições como o teor de água utilizado e a velocidade de rotação empregada exercem influência significativa sobre as características do produto final. O uso da câmara de mistura acoplada ao reômetro de torque como ferramenta auxiliar na determinação do comportamento de fluxo do material mostrou ser vantajosa como teste preliminar de definição dos parâmetros de extrusão. A utilização das técnicas de RVA e de microscopia óptica como análises complementares ao processamento em câmara de mistura foi eficiente para comprovar as respostas fornecidas por meio das curvas de torque.

\section{5 - REFERÊNCIAS BIBLIOGRÁFICAS}

[1] AKDOGAN, H. Pressure, torque, and energy responses of a twin screw extruder at high moisture contents, Food Research International, v. 29, n. 5-6, p. 423-429, 1996

[2] BECKER, A.; HILL, S.E.; MITCHELL, J.R. Milling - A further parameter affecting the Rapid Visco Analyser (RVA) Profile. Cereal Chemistry, v. 78, n. 2, p. 166-172, 2001.
[3] BILIADERIS, C. G., MAURICE, T. J. \& VOSE, J. R. Starch gelatinisation phenomena studied by differential scanning calorimetry. Journal of Food Science, v. 45, n. 6, p. 1669-1680, 1980.

[4] BULÉON, A., COLONNA, P., PLANCHOT, V. Starch granules: structure and biosynthesis. International Journal of Biological Macromolecules, v. 23, n. 2, p. 85-112, 1998.

[5] BYRNE, R. What Is A Torque Rheometer? In: Technical Bulletin. New Jersey: HaakeBuchler Instruments, Inc., 1984. pp. 1-6.

[6] CAI, W. \& DIOSADY, L.L. A model for gelatinisation of wheat starch in a twin-screw extruder. Journal of Food Science, v. 58, n. 4, p. 872-875, 1993.

[7] CAI, W. \& DIOSADY, L.L. Degradation of wheat starch in a twin-screw extruder. Journal of Food Engineering, v. 26, n. 3, p. 289-300, 1995.

[8] DONOVAN, J.W. Phase transitions of starch - water system. Biopolymers, v. 18, n. 2, p. 263-275, 1979.

[9] FICHATALI, J.; VAN DE VOORT, F.R. Fundamental and practical aspects of twin screw extrusion. Cereal Foods World, v. 34, n. 11, p. 921-929, 1989.

[10] FUKUOKA, M., OHTA, K.-I., \& WATANABE, H. Determination of the terminal extent of starch gelatinisation in a limited water system by DSC. Journal of Food Engineering, v. 53, n. 1, p. 39-42, 2002.

[11] GOMEZ, M.H., AGUILERA, J.M. Changes in the starch fraction during extrusion cooking of corn. Journal of Food Science, v. 48, n. 2, p. 378-381, 1983.

[12] HARPER, J. M. Extrusion of foods, v.1, CRC Press Inc., Boca Raton, 1991.

[13] HOLM, J., BJORCK, I., ELIASSON, A.C. Effects of thermal processing of wheat and starch: II. Physicochemical and functional properties. Journal of Cereal Science, v. 8, n. 3, p. 145-152, 1988.

[14] KARAPANTSIOS, T.D., SAKONIDOU, E.P., RAPHAELIDES, S. N. Water dispersion kinetics during starch gelatinisation. Carbohydrate Polymers, v. 49, n. 4 , p. $479-490.2002$

[15] LAI, L.S., KOKINI, J.L. Physicochemical changes and rheological properties of starch during extrusion. Biotechnology Progress, v. 7, n. 3, p. 251-266, 1991.

[16] LELIEVRE, J. Starch Damage. Starch/Stärke, v.26, p. 85-88, 1974.

[17] LOURDIN, D.; COIGNARD, L.; BIZOT, H. Influence of equilibrium relative humidity and plasticizer concentration on the water content and glass transition of starch materials. Polymer, v. 38, n. 21, p. 5401-5406, 1997.

[18] MANI, R.; BHATTACHARYA, M. Properties of injection moulded starch/synthetic polymer blends - III. Effect of amylopectin to amylose ratio in starch. European Polymer Journal, v. 34, n. 10, p. 1467-1475, 1998.

[19] MITCHELL, J.R., HILL, S.E., PATERSON, L., VALLĖS, B., BARCLAY, F., BLANSHARD, J.M.V. The role of molecular weight in the conversion of starch. In: FRAZIER, P.J.; DONALD, A.M.; RICHMOND, P. (Eds.) Starch structure and functionality. London: The Royal Chemistry Society, 1997. pp. 69-76.

[20] OLKKU, J., RHA, C. Gelatinisation of starch and wheat flour starch - a review. Food Chemistry, v. 3, n. 4, p. 293-311, 1973.

[21] OLLET, A.-L., PARKER, R., SMITH, A.C., MILES, M.J., MORRIS, V.J. Microstructural Changes during the Twin-Screw Extrusion Cooking of Maize Grits. Carbohydrate Polymers, v. 13, n. 1, p. 68-84, 1990. 
[22] RYU, G.H., NEUMANN, P.E. \& WALKeR, C.E. Pasting of wheat flour extrudates containing conventional baking ingredientes. Journal of Food Science, vol.58, n.3, p.567-573, 1993.

[23] THIRÉ, R.M.S.M.; SIMÃO, R.A.; ANDRADE, C.T. High resolution imaging of the microstructure of maize starch films. Carbohydrate Polymers, vol.54, n2, 2003.

[24] WALKER, C.E., ROSS, A.S., WRIGLEY, C.W., McMASTER, G.J. Accelerated starch-paste characterization with the rapid visco-analyzer. Cereal Foods World, vol.33, n.6, p.491-494, 1988.
[25] WHALEN, P.J., BASON, M.L., BOOTH, R.I. Measurement of extrusion effects by viscosity profile using the rapid viscoanalyser. Cereal Foods World, vol.42, n.6, 1997.

\section{6 - AGRADECIMENTOS}

Os autores agradecem ao CNPq pelo apoio financeiro e à Coladesi Indústrias Químicas Ltda. por terem gentilmente cedido o amido de milho utilizado nestes experimentos. 